\title{
口 O O lugar da identidade gênero na literatura brasileira
}

\section{Carlos Magno Gomes}

Prof. Adjunto de Literatura do Campus Prof. Alberto Carvalho e do Mestrado em Letras da Universidade Federal de Sergipe. Doutor em Literatura pela UnB, com pós-doutorado em Letras Vernáculas pela Universidade Federal do Rio de Janeiro. E-mail: calmag@bol.com.br.

RESUMO: Este trabalho retoma a reflexão acerca da identidade de gênero nos romances de Clarice Lispector, Lygia Fagundes Telles, Lya Luft e Helena Parente Cunha, a partir da proposta radical de Judith Butler de haver identidade sem sujeito e da leitura do roteiro estético de cada obra. Partindo de uma concepção feminista, analisa-se o não-lugar da identidade de gênero não só como resistência ao patriarcado, mas também como uma proposta pedagógica da literatura. Tal contestação é sugerida pela representação da identidade liquida, pela exploraçāo da identidade em trânsito, pelo enterro da maternidade e pelo uso do paródico e do patético, respectivamente, em cada autora.

Palavras-chave: feminismo; identidades; literatura brasileira
ABSTRACT: This article reflects upon gender identity in Clarice Lispector's, Lygia Fagundes Telles', Lya Luft's and Helena Parente Cunha's novels, by resorting to Judith Butler's radical proposal regarding the existence of identity without a subject and to the reading of the aesthetic script in each work. Taking a feminist conception as a starting point, not only is the "no-place" of gender identity analyzed as a form of resisting patriarchy, but also as literature pedagogical proposition. Such contention is suggested by the representation of liquid identity, by the exploration of transit identity, by the burial of motherhood and by the uses of parodic and pathetic elements, respectively, in each author.

Keywords: feminism; identities; Brazilian literature 

Na literatura brasileira do século XX, os romances de autoria feminina representam diferentes tensões entre a identidade de gênero padronizada pela família e a identidade transgressora das protagonistas. Essa forma privilegiada de descentramento do sujeito masculino foi iniciada por Clarice Lispector com protagonistas quase "selvagens" e experimentada de diferentes formas por Lygia Fagundes Telles, Nélida Piñon, Lya Luft, Helena Parente Cunha, Marina Colassanti e Patrícia Bins, entre outras. Suas narrativas apresentam mulheres transgressoras que abandonam a identidade feminina tradicional por não se identificarem com a imposição de papéis tipicamente femininos. Vale ressaltar que, em alguns romances, as protagonistas não têm uma realização social completa, mesmo assim, a identidade transgressora fica registrada como um marco de resistência da mulher. Tal significado da imagem da transgressora reforça a ideia de um nãolugar para a identidade de gênero como um lugar de resistência na tradição da autoria feminina brasileira.

Artisticamente, mesmo sem a construção de um sujeito feminino plenamente realizado, a literatura dessas escritoras se projeta como uma resistência feminista, vistu que o processo de construção de uma nova identidade de gênero foi concluído no campo estético. Seus textos têm também um status pedagógico por dar visibilidade à opressão patriarcal. Nessa perspectiva, a representação da identidade de gênero fora do lugar faz parte do projeto literário dessas escritoras, quando constroem personagens femininas sufocadas pelos espaços patriarcais. Tal relação entre espaço e identidade está proposta no roteiro da narrativa, isto é, na forma como o texto se desdobra tanto esteticamente quanto ideologicamente. Ora, se "a construção do gênero é tanto o produto quanto o processo de sua representação" (LAURETIS, 1994, p. 211), então, no texto literário, diversas questões estéticas entram no jogo da interpretação. Por esse princípio, a crítica literária pode problematizar sua interpretação a partir dessas opções estéticas e evitar o simples jogo do binarismo entre 
${ }^{1}$ Os pressupostos teóricos que estruturam este artigo foram apresentados no IV Colóquio Nacional de Representação de Gênero e

Sexualidade que aconteceu na UEPB, Campina Grande, nos dias 13 e 14 de junho de 2008. o "masculino" e o "feminino" que envolve a construção da identidade de gênero.

Neste ensaio, retomo alguns pontos-chave acerca de como a identidade de gênero é representada no texto de autoria feminina. ${ }^{1}$ Para isso, parto de uma análise literária que não deixa de lado as opções estéticas como um lugar de resistência ideológica da escritora brasileira no Século XX. No primeiro momento, problematizo a relação entre forma literária e identidade de gênero. Em seguida, traço um panorama de como o não-lugar de gênero é tradicionalmente usado pelas escritoras brasileiras como um lugar de produção de novos pertencimentos identitários. Finalizando, defendo uma metodologia de leitura que analisa o espaço estético da obra literária como um lugar de resistência feminista. Dessa forma, proponho a valorização do plano estético do texto como princípio norteador do estudo da identidade de gênero. Portanto, a premissa aplicada aqui é a de repensar os textos de Clarice Lispector, Lygia Fagundes Telles, Lya Luft e Helena Parente Cunha como uma representação que liberta o discurso de gênero das amaras disciplinadoras da sociedade. Neste jogo de leitura, o espaço literário é composto de intersecções, nem mera representação, como também não é apenas a imanência absoluta da escrita, por isso o/a leitor(a) deve se concentrar no processo de construção da identidade a partir das opções estéticas que o texto nos oferece.

A flexibilidade da identidade de gênero foi fortalecida pela crítica ao patriarcalismo, que foi construída, ao longo dos anos, principalmente, pelas teóricas feministas. Tal crítica não se projeta nem de forma homogênea, nem monolítica, pois se constitui "num complexo de visões práticas articuladas em torno de um ponto de vista comum: a contestação do patriarcado" (XAVIER, 1999, p. 16). Tanto quanto a teoria, o texto de autoria feminina não apresenta estratégias homogêneas para o descentramento do discurso patriarcal. Outro aspecto relevante é o fato de a identidade ser um processo 
sempre em movimento, que não apresenta fixidez, pois se trata de uma prática social plural. Daí a importância de um estudo da identidade de gênero a partir de uma posição deslocada, de um lugar de suturação, de rasuras, de um sujeito de fronteiras (cf. HALL, 2000).

Com as novas abordagens teóricas, sabemos que a identidade de gênero é fruto, acima de tudo, da repetição de atos performáticos. Ela não é dada, nem brota biologicamente do ser. Pelo contrário, ela é consequência de um longo processo de identificação e de escolha que envolve rejeição e aceitação, visto que "o sujeito não é determinado pelas regras pelas quais é gerado, porque é antes um processo regulado de repetição que tanto se oculta quanto impõe suas regras, precisamente por meio da produção de efeitos substancializantes" (BUTLER, 2003, p. 209). Além disso, no texto literário, a identidade de gênero é bem mais ambígua, pois está atravessada pelo dialogismo textual.

$\mathrm{Na}$ ficção, as regras impostas pelas personagens transgressoras tornam-se relevantes para a fragmentação da sociedade patriarcal. Todavia, cabe ao crítico literário fazer uma releitura dessas representações a partir do político, uma vez que a literatura é polissêmica e nunca é simplesmente mimética e transparente. Fugir do binarismo tradicional é reconhecer o fato de que qualquer representação é uma construção feita por meio das diferenças (HALL, 2000, p. 108-10). Para isso, é importante reconhecer que a identidade de gênero é uma construção e um resultado de um ato de naturalização, pois "é um "ato", por assim dizer, que está aberto a cisões, sujeito a paródias de si mesmo, a autocríticas àquelas exibições hiperbólicas do "natural" que, em seu exagero, revelam seu status fundamentalmente fantasístico" (BUTLER, 2003, p. 211). Além de reconhecer o status "fantasístico" de uma identidade, é pertinente destacar que qualquer identidade faz parte de um ciclo de identificação: o pertencimento. Nesse processo, o novo e o velho se encontram, em um espaço rasurado, já que ele "não pode 
ser pensado de forma antiga, mas sem a qual certas questões-chave não podem ser sequer pensadas" (HALL, 2000, p. 104).

Cabe ressaltar que, no espaço artístico, a análise deve evitar o ângulo unidirecional, pois o espaço estético antes de tudo "recria e transforma, produzindo cortes e intervalos entre corpo, trajeto biográfico-social, posições de gênero, traços subjetivos e figurações textuais" (RICHARD, 2002, p. 161). Isso é muito importante, pois não estamos preocupados com o final feliz da protagonista, visto que nas representações identitárias há "significados suplementares sobre os quais não temos qualquer controle, que surgirão e subverterão nossas tentativas para criar mundos fixos e estáveis" (HALL, 1999, p. 41). Para este ensaio, faço uma análise das representações de protagonistas transgressoras nas obras O lustre (1946), de Clarice Lispector, Ciranda de pedra (1954), de Lygia Fagundes Telles, O quarto fechado (1984), de Lya Luft, e As doze cores do vermelho (1987), de Helena Parente Cunha.

\section{A condição líquida do pertencimento}

Logo que surgiram, as personagens de Clarice Lispector assustaram por sua condição líquida. Por exemplo, Virgínia, protagonista de O lustre (1946), apresenta uma identidade em construção por estar sempre à procura de algo, mostrando "a fragilidade e condição eternamente provisória da identidade" (BAUMAN, 2005, p. 22). Essa obra traduz o conflito da identidade de gênero a partir do estranhamento da mulher com a modernidade. Daí a ideia de Virgínia não apresentar um pertencimento definido. Quando criança, Virgínia e Daniel, seu irmão, fazem um estranho pacto de cumplicidade: "A Sociedade das Sombras aproximava-a tanto de Daniel!” (LISPECTOR, 1999 , p. 55). Contudo, depois que vão viver no centro urbano, os dois seguem caminhos diferentes. Daniel se casa e volta para a granja dos pais, Virgínia continua errante na cidade até decidir voltar a viver com a família. 
Virgínia traduz uma condição líquida por se fragmentar na busca de um equilíbrio psicológico. Ela vive um mundo pessoal. Distancia-se de uma referência externa para se aproximar de algo seu. Ela sempre é descrita como um sujeito fora do lugar e vazia de si: "sem se entender, sentindo um certo vazio no coração, pareceu-lhe ainda que na verdade perdera uma de suas coisas" (LISPECTOR, 1999 , p. 255). Virgínia foge do campo para a cidade, mas não se sente culturalmente vinculada a nenhum desses espaços. Os espaços sociais a oprimem, como, por exemplo, os móveis da casa paterna "em vez da aconchegante riqueza que o tapete anunciava encontravam-se o vazio, o silêncio e a sombra" (LISPECTOR, 1999, p.14). Desse espaço opressor, Virgínia está sempre fugindo.

Assim, por se projetar fora do sistema, Virgínia traduz o não pertencimento identitário, pois opta por não pertencer a nenhum espaço externo, somente a ela mesma: "Ela seria fluida durante toda a vida. Porém o que dominara seus contornos e os atraíra a um centro, o que a iluminara contra o mundo e lhe dera íntimo poder fora o segredo" (LISPECTOR, 1999, p. 09). Daí a condição líquida da identidade de Virgínia, pois ela não pertence nem ao espaço urbano, nem ao rural, condensando uma identidade de múltiplas exclusões. Benedito Nunes, um dos leitores mais completos de Lispector, destaca que Virgínia é marcada pelo ritmo da procura, a ação é uma trajetória, uma errância "que se perfaz como movimento de evasão ou fuga" (NUNES, 2005, p. 27). Esse movimento psicológico da protagonista pode ser visto como uma a busca de um pertencimento identitário.

Ora, mesmo se tratando de uma protagonista que não apresenta um encontro consigo mesma, observa-se que seu não-espaço opõe-se à identidade feminina tradicional. Pelo visto, Virgínia ressalta a "crise do pertencimento", pois ela transpõe a brecha "entre o 'deve' e o 'é' e erguer a realidade ao nível dos padrões estabelecidos pela idéia" (BAUMAN, 2005, p. 26). Sua 
identificação parte de suas ideias, do seu pensamento, ela não está voltada para o espaço que a cerca, por isso sua identidade propõe a ruptura e a sutura, elementos próprios de um sujeito deslocado.

Com essa representação deslocada, a autora opta pela construção de uma identidade que não consegue se fixar em nenhum espaço. Por exemplo, no final da narrativa, quando desesperadamente abandona a casa dos pais, mais uma vez Virgínia se vê em processo de busca: "sentia-se alegre, como fria e fresca por dentro. De novo só começava a experimentar 'as coisas', a permiti-las" (LISPECTOR, 1999, p. 253). Assim, em O lustre, o conflito entre a identidade moderna e a identidade patriarcal proporciona uma constante busca identitária para Virgínia. A autora não opta por simples binarismos, nem por posições definitivas para a protagonista. Como Virgínia não consegue se adequar à vida urbana, mas também não se sente bem nos cômodos dias da casa de seus pais, ela foge para a cidade sem rumo certo. Parece que seu rumo certo é fora do lugar.

Sem caber em nenhum dos espaços, ela se projeta fora dos papéis naturalmente impostos à mulher. Já no fim de seu desespero, a protagonista "fumava e pensava inexplicável, sem se alcançar. E na verdade como pressentir jamais o que sucedia sem interrupção dentro do mais ser de seu corpo?" (LISPECTOR, 1999, p. 254). Essa condição líquida da identidade de Virgínia pode ser vista como recurso estético inovador para a representação de uma protagonista transgressora. De uma forma metonímica, a negação de um referencial social a Virgínia também é relevante. Com isso, O lustre privilegia a identidade da diferença, como própria de um espaço de abjeção: “o sujeito é constituído através da força da exclusão e abjeção, uma força que produz um exterior constitutivo" (BUTLER, 2001, p. 155). A partir dessa abjeção, o texto de Lispector impõe o olhar de ruptura e sutura das verdades disciplinadoras da identidade submissa que era destinada à mulher na família patriarcal. 
Ainda vale destacar que, no texto, não só a protagonista é fluida, mas a linguagem e o próprio enredo dessa narrativa. Além desse status "líquido" da narrativa, a performance identitária de Virginia se destaca por ela exercitar aos extremos o lado "fantasístico" da identidade. Partindo da premissa de que a admissão de uma nova identidade é considerada uma alteração essencial, uma alteração que atinge a "essência" do sujeito (cf. LOURO, 2001, p. 13), Virgínia consegue uma nova identidade longe do domínio da família, ao se projetar fora do lugar. Seu caráter transgressor é menos coletivo que pessoal. Portanto, sua identidade líquida não envolve o ritual doméstico feminino, nem o conformismo com os papéis sociais que lhe são impostos. Mesmo sendo atropelada e morrendo no final da narrativa, a trajetória identitária de Virgínia fica consolidada. Para ela, estar fora dos espaços dos outros assegura sua busca pessoal. Essa busca é um não-lugar da identidade de gênero, um espaço de resistência estética e social. Dessa forma, podemos dizer que Lispector antecipa um dos conflitos mais comuns às identidades pós-modernas, a perenidade do pertencimento identitário.

\section{A identidade em trânsito}

Outro romance que faz parte dessa tradição de representação da protagonista fora do lugar é Ciranda de pedra, de Lygia Fagundes Telles. Essa obra parodia os tradicionais romances de formação feminina por apresentar uma protagonista que se opõe ao discurso do pai. Virgínia, a protagonista, rompe com a família patriarcal, numa metáfora da parricida, a que mata o pai. As opções temáticas dessa obra e a forma como o texto é narrado também apresentam uma identidade transgressora que tanto pode ser apontada no texto social como no estético. Quanto à recepção crítica dessa escritora, vale destacar que suas narrativas dão destaque aos conflitos familiares. Para Elódia Xavier, "o universo ficcional de Lygia Fagundes Telles é marcado por essa ausência do pai, isto é, pela 
desestruturação familiar; e daí decorrem os conflitos das personagens" (XAVIER, 1998, p. 44). Além disso, sua obra reproduz a crise do patriarcado, a partir do descentramento da figura do pai: "Em seus três primeiros romances o ponto de vista narrativo principal pertence à mulher e enfoca relações dentro das quais o homem já não tem poder determinante" (PINTO, 1990, p. 119).

Ciranda de pedra está estruturada em duas fases: na primeira, Virgínia é descrita como uma criança indisciplinada e deselegante por não apresentar modos refinados. Ainda nessa parte, Virgínia descobre que é uma filha ilegítima, por isso, foge do pai traído, Natércio, viajando para um internato. Na segunda fase do romance, Virgínia, com uma formação intelectual, volta para o convívio burguês de uma família de aparências e falsidades. Mesmo tendo amadurecido psicologicamente, ela não consegue entrar no círculo de amizades das irmãs por não aceitar as regras sociais impostas.

As constantes fugas de Virgínia formam um grupo de metáforas que consolidam seus conflitos de pertencimento identitário. Pode-se dizer que, quando ela se distancia do padrão, há uma recusa de 'integração' no grupo social a favor de uma integração do sujeito feminino (cf. PINTO, 1990, p. 150). A concomitância da formação dessa personagem e do discurso ideológico que permeia a obra aponta um paralelo entre literatura e sociedade, uma vez que descentra valores hegemônicos. Assim, a relação entre a identidade de Virgínia e a do espaço patriarcal é articulada como um conjunto de signos que remetem às opções estéticas feministas. Isso pode ser identificado pelo fato de Virgínia fugir dos espaços que são descritos como adequados para uma moça bem educada.

Nesse sentido, por exemplo, a. metáfora da fuga de Virgínia pode ser lida como a busca por um espaço em "outro ponto" para a mulher. Seu espaço é descrito como um "espelho despedaçado" e "partido em mil pedaços" (TELLES, 1998, p. 57). Nessa metáfora do espelho quebrado, está a representação de uma família 
desmontada. Observa-se que esses pequenos resumos do enredo funcionam como textos paralelos da condição da mulher. O deslocamento que Virgínia representa enquanto identidade feminina traz rastros de uma memória da qual quer se livrar como, por exemplo, quando abandona o convívio do pai, logo após a morte de Laura, sua mãe: "Sempre quis ficar interna num colégio. Por favor, pai, eu não quero morar aqui" (TELLES, 1998, p. 87). O pertencimento de Virgínia caracteriza-se como o de uma errante que vaga pelos diversos espaços sociais desde a casa da mãe doente, passando pela casa do pai biológico, pelo espaço disciplinante do internato, até o espaço das ambíguas relações afetivas e sexuais entre suas irmãs e amigos: "A estranha ciranda! Eram solidários e no entanto se traíram" (TELLES, 1998, p. 149). Devido às atitudes de desmoralização dos comportamentos familiares, a ciranda em volta do patriarcado está fadada ao fracasso social, pois se alimenta do jogo de aparências. Em nenhum desses lugares, Virgínia se encontra. Ela está sempre em trânsito, de passagem, experimentando diversas formas de pertencimento identitário.

A ideia de fuga fortalece o perfil feminista desse romance. Primeiro, Virgínia foge da mãe louca e pobre, depois foge do luxo da casa do pai rico, e, por último, faz uma terceira viagem, a de abandono do estado "fantasístico" das identidades que compõem sua família. Com isso, temos um plano estético que deixa em aberto a consolidação da identidade feminina transgressora. Descontente com aquelas relações de aparências, ela opta por uma viagem sem destino. Como num ritual de purificação, essa protagonista se renova na fuga, pois deixa para trás marcas de sua rejeição: "De repente ouviu a própria voz incisiva: "Decidi viajar. Mas uma longa viagem sem passagem de volta, pelo menos por enquanto" (TELLES, 1998, p. 178). A ideia da fuga e da viagem identitária atravessa a construção dessa obra. Com isso, Ciranda de pedra retrata uma mulher descontente com sua situação social e que busca novos espaços, traduzindo 
uma experiência feminista. Então, Virgínia opõe-se aos comportamentos herdados e ganha um status da diferença, pois tal identificação faz parte da construção do seu EU, uma vez que "as identidades são construídas por meio da diferença e não fora dela" (HALL, 2000, p. 110).

Cristina Ferreira Pinto aponta as marcas transgressivas dessa obra, quando elege Virgínia como uma das primeiras protagonistas da literatura brasileira a trilhar um caminho diferente do patriarcal sem ser punida com a loucura, doenças ou mutilações comuns aos romances de formação feminina tradicional. Virgínia rompe com "as limitações sociais e atinge a independência e afirmação pessoal desejadas, assumindo uma posição marginal que é agora escolha, liberação" (PINTO, 1990, p. 149). A escolha de um novo caminho, de uma trajetória pensada, faz a diferença nesse romance. As metáforas das viagens próprias de uma identidade transgressora e as opções estéticas dessa narrativa condensam uma identidade de gênero resistente e oposta ao fixo e ao padronizado. O estado de trânsito de Virgínia se aproxima da condição do não-lugar já sugerido pela narrativa de Clarice Lispector.

\section{O enterro da identidade patriarcal}

Mesmo depois da consolidação do pensamento feminista nas décadas de sessenta e setenta do Século XX, a literatura de autoria feminina continuou preocupada em representar a mulher transgressora da família patriarcal. Dessa fase, Lya Luft é uma das escritoras mais estudadas por esse fenômeno cultural. Suas obras apresentam uma extensa galeria de personagens rejeitadas pelos aspectos estranhos e transgressivos dentro da família patriarcal. Em O quarto fechado (1984), o palco familiar desabou, seus atores estão em processo de juntar os cacos que sobraram de um espaço opressor e intrigante. Renata, a protagonista, depara-se com o velório do filho suicida, Camilo. Ao mesmo tempo em que vela o filho, Renata, uma pianista de sucesso que abandona a carreira por um casamento, 
reconstrói sua identidade subjetivamente a partir de um não-lugar na família patriarcal.

Nas obras de Lispector e Telles, as protagonistas eram mulheres solteiras, livres que, mesmo fazendo parte de uma família patriarcal, conseguem ocupar as fronteiras dos espaços patriarcais. Já nas obras de Lya Luft, as protagonistas são casadas e a liberdade da mulher é uma ameaça à ordem da família. Nesse contexto, a liberdade da mulher casada pode ser vista como uma ameaça, visto que “a 'individualização' em excesso são bênçãos ambíguas. Oscilam entre o sonho e o pesadelo, e não há como dizer quando um se transforma no outro" (BAUMAN, 2005, p. 38). Em O quarto fechado, essa ambiguidade é experimenta pelo patriarca, Martim. Para ele, e para os filhos, Camilo e Carolina, a mãe, Renata, é um pesadelo, pois está em busca de novos pertencimentos identitários.

Nessa obra, Renata busca encontrar uma linguagem que corresponda ao seu estágio social diante do filho morto. Por isso, volta-se para o contexto interior, num processo introspectivo. Renata vai pintando novas imagens para si, a partir da fusão das imagens do quadro "Ilha dos mortos" e o velório de Camilo, um "espetáculo inaugural" (LUFT, 1991, p. 83) de uma travessia simbólica da mulher silenciada. À medida que a noite avança, Renata relê a opção do filho, ao se projetar no espaço da morte: "recoberto de uma poeira dourada, perdera a juventude e ostentava aquela máscara solene: cera, gelo, uma nova sabedoria" (LUFT, 1991, p. 13). Assim como nas obras de Lispector e Telles, o campo estético da narrativa possibilita uma leitura mais sofisticada da identidade de gênero. Ao vivenciar a morte do filho, Renata também se enterra. Por meio desse processo metafórico, O quarto fechado possibilita a leitura da morte da identidade materna tradicional. O fracasso dessa representação é muito bem articulado entre a subjetividade da artista, a opressão do marido e as ambiguidades de gênero propostas pelos gêmeos Camilo e Carolina. 
A partir da interação da superfície do quadro com a imagem do velório, os contextos estéticos e sociais se reordenam numa rede de novos referenciais. Isso só é possível com uma leitura que rompa com as fronteiras físicas do quadro e funda esses dois universos. Quadro e realidade se completam pelo olhar de Renata "tudo vibrava, palpitava, por trás da cena imóvel. Ela conseguia respirar aquele ar pesado, tatear os contornos das muralhas contra o fundo sombrio. Janelinhas, ciprestes, uma água de vidro negro. Um barco dirigia-se para lá; na proa, em pé, um vulto embuçado" (LUFT, 1991, p. 19). Nessa releitura da morte, o corpo de Camilo ganha status de texto: "Renata mirava Camilo: por onde andaria agora? Morto, parecia-lhe um pouco menos misterioso" (LUFT, 1991, p. 62). Nessa atmosfera gótica, o quadro remete o/ a leitor/a a um resumo do romance, pois ressalta a situação solitária de Renata, fora dos espaços tradicionais.

Ao sobrepor as fronteiras do quadro às de seu contexto, Renata consegue se ver melhor. Essa travessia se completa quando percebe que ela própria guiava o filho para a Ilha: "O quadro ainda pendia torto, belo e consolador. Então, chegando ao fim das suas forças, Renata compreendeu: Não era um barqueiro: era uma mulher. O vulto da proa era ela, a Amada de Camilo: Thanatos" (LUFT, 1991, p. 130). Dessa forma, Renata completa sua leitura que significa um trajeto revelador de si mesma: uma mãe que guia o filho pelos espaços da morte. Assim, sem a consolidação de uma maternidade tradicional, ela deixa aberta uma perspectiva feminista, pois, com o filho, Renata enterra também um casamento patriarcal do qual não queria mais participar.

A partir dessa leitura, O quarto fechado não registra uma identidade fixa, nem concluída para o sujeito feminino, optando por representar um ambiente decadente para a família. Nesse sentido, o jogo estético propõe um nãolugar para a identidade da mãe, um lugar que pode ser lido como abandono. Com isso, essa obra traduz as complicações da identidade de gênero que "envolve rituais, 
linguagens, fantasias, representações, símbolos, convenções... Processos culturais e plurais" (LOURO, 2001, p. 11). Com tais opções estéticas, Lya Luft prioriza uma perspectiva ideológica feminista para a representação da mulher. Nesse tipo de construção artística, as interpretações tradicionais se tornam frágeis e não dão conta das tensões entre o estético e o social articulado no roteiro da narrativa.

Portanto, nessa obra, a relação entre forma e conteúdo literário propiciam dinâmicas leituras, uma vez que, no texto literário, identificamos diferentes posições discursivas responsáveis pelo jogo metafórico. Como tento exemplificar neste trabalho, a identidade de gênero de Renata sustenta esse não-lugar como uma oposição à identidade materna da mulher. A ideia do fora do lugar é o tempo todo articulada no interior da obra. A sofisticação dessa construção narrativa só foi retomada por Lya Luft com $A$ sentinela (1994), obra em que a mulher ganha um espaço para pensar seu processo de pertencimento identitário como algo sempre em movimento. Dando continuidade, vamos explorar a representação da protagonista transgressora no texto de Helena Parente Cunha.

\section{A identidade artística contestadora}

$\mathrm{Na}$ tradição das protagonistas transgressoras construídas pelas escritoras brasileiras, podemos incluir a obra As doze cores do vermelho (1987), de Helena Parente Cunha. Essa obra tem as características de um romance de formação feminina, por trazer uma protagonista que faz reflexões acerca do seu pertencimento identitário desde menina, quando brinca com seus amigos. Helena P. Cunha propõe, explicitamente, a representação do espaço da mulher artista como um espaço de diferença e de resistência. A protagonista é uma pintora. Ela é casada e busca novos espaços para sua identidade artística fora do espaço da família. Assim como Renata, essa protagonista torna-se um pesadelo para o marido e para as filhas. $O$ 
${ }^{2}$ A narrativa de $A s$

Doze Cores do

Vermelho acontece em

três ângulos. Usarei, após o número de cada página, os seguintes códigos: A1 para o ângulo $1, \mathrm{~A} 2$ para o ângulo 2 e A3 para o ângulo 3. plano estético de As doze cores do vermelho apresenta uma saída que também propõe um jogo metafórico do enredo para não cair na cilada do binarismo. A protagonista narra suas experiências de um lugar ambíguo ao identificar novas possibilidades identitárias fora do binarismo. Tal subversão discursiva contesta a identidade fixa e a família como sistema totalizante ou homogêneo. A autora constrói uma narrativa voltada para a fragmentação da mulher, propondo-lhe uma perspectiva individual como estratégia de ruptura com a tradição.

A integração pessoal da mulher pode ser lida como uma preocupação feminista desse texto que subverte as normas culturais. A autora propõe o abandono dos binarismos próprios do mundo patriarcal com uma estrutura textual tripartida. Para cada módulo (capítulo), há três ângulos da história da protagonista: à esquerda, o passado vivido; ao centro, a vida presente; e à direita, seu futuro de libertadade:

Eu era uma menina como as outras que brincava no arco da manhã repleta de alvoradas ... Nós brincávamos de casinha comidinha de mãezinha das bonecas. Os meninos brincavam de soldado espingarda revólver de espoleta. As meninas do lado de cá e os meninos do lado de lá (CUNHA, 1998, p. $14, \mathrm{~A} 1)^{2}$.

Essa narrativa é extremamente fragmentada, exigindo do/a leitor/a uma percepção para o entendimento da proposta do texto. As ações da protagonista são reveladas sem uma sequência cronológica determinada, pois o enredo vai se amarrando conforme a consolidação da proposta subversiva da autora. Em sua travessia, a protagonista parte de uma situação de aparente equilíbrio, contudo ela apresenta, desde a infância, uma postura crítica sobre o universo de normas e regras a serem enfrentadas. Sua trajetória é a de uma identidade pósmoderna, pois questiona os conceitos do humanismo liberal 
como totalização, verdade, identidade, certeza, centro, homogeneidade, dentre outros, num discurso pós-moderno que privilegia a diferença como um referencial de interpretação (cf. HUTCHEON, 1991, p. 84).

Nessa obra, a identidade de gênero busca explicitamente um terceiro espaço fora dos binarismos tradicionais: "Duas metades. Dois lados. Dois quartos. O apartamento de dois quartos" (CUNHA, 1998, p. 33, A3). Observa-se também que a opressão por uma escolha simplificada faz parte do pertencimento da artista. Por exemplo, quando ela se casa e abandona seus sonhos: "Você não vai mais entrar para a escola de belas artes. Você prometeu a seu noivo que não vai mais pintar. Ele elo. Você está preparada para o casamento" (CUNHA, 1998 , p. 15, A2). Com a frustração do casamento, a mulher começa a rever seus papéis sociais, por isso "ela lerá muitos medos e muitas coragens. O lado de lá e o lado de cá" (CUNHA, 1998, p. 21, A3). Mais adiante o casamento é descrito como: "Escassez definhável encurtar encurralavelmente, Você se cansa. Cansaço cósmico" (CUNHA, 1998, p. 47, A2). Essa tentativa de experimentar os diversos papéis para uma mulher no casamento aponta o caráter mais dinâmico dessa obra.

Como um discurso de oposição ao centro, a protagonista produz sua arte: "ninguém poderá entender aqueles quadros de profusões e florações e doze badaladas da meia-noite no meio-dia" (CUNHA, 1998, p. 47, A2). As leituras oferecidas por seus quadros revelam o quanto o universo familiar era opressor dos desejos sociais da mulher. Apontando a saída no seu próprio "eu", a autora usa o não-lugar como uma identidade possível, uma ponte responsável por sua ligação ao mundo externo: "Além dos dois lados o ápice estrelado da cordilheira" (CUNHA, 1998, p. 100, A2). Ao se ver fora da família, a protagonista completa um ciclo de identificação que só é possível porque sua identidade está sendo "construída multiplamente ao longo dos discursos, práticas e posições que podem se cruzar ou ser antagônicas" (HALL, 2000, p. 108). Por 
esse viés interpretativo, o processo de identificação dessa obra artística é fundamental para se entender o projeto feminista que entrecruza o projeto artístico do romance.

Essa ideia de amplitude, oferecida pelo texto, é valiosa se vista como o discurso crítico a tudo que é opressão à mulher. $\mathrm{O}$ fato de ela não mais ver a dicotomia que lhe oprime, durante todo seu processo de crescimento, mostra-se compensador, como se realmente ela estivesse para alcançar um novo estágio, sem extremos e que oferecesse mais opções para suas individualidades. A protagonista dessa obra morre em um acidente de carro e mais uma vez nos deparamos com uma obra sem um sujeito feminino consolidado. Nesse sentido, prevalece o não-lugar da identidade de gênero como uma oposição ao imposto e uma saída estética de ruptura com a lógica social de gênero. Como explorado neste artigo, o lugar para a identidade de gênero transgressora é o fora do lugar da tradição.

No plano artístico, As dozes cores do vermelho pode proporcionar um novo olhar para a identidade de gênero, se visto como uma paródia do casamento tradicional. Diante disso, o texto cumpre seu papel de denunciar e de propor a individualização da mulher como um outro lugar de gênero, visto que a travessia pela qual a protagonista se envereda representa a rejeição da norma. Com isso, há uma recusa do padrão de gênero que lhe era cobrado pelo marido e pela filha doente. Nesse sentido, Judith Butler chama a atenção para as imposições culturais da identidade de gênero e sexual como construtos sociais, pois "a desigualdade de gênero e a opressão sexual não são fatos imutáveis da natureza, mas sim artefatos da história" (BUTLER, 2001, p. 144). Essa protagonista que opta por encontrar o seu próprio caminho está denunciando o sistema cultural que sempre propôs para a mulher um lugar "natural" diante da dominação masculina.

Nessa obra, por apresentar a trajetória de uma artista, as opções estéticas se confundem com as opções temáticas, visto que a subversão e a ruptura das normas 
estão simbolicamente marcadas com as ações da protagonista. Assim como apontado nas obras de Lispector, Telles e Luft, o romance de Helena Parente Cunha também apresenta um não-lugar como uma opção estratégica para a identidade de gênero transgressora. Tal como acontece com as outras protagonistas analisadas neste artigo, a identidade de gênero tradicional não foi consolidada. Dentro da construção estética dessa obra, isso significa que essa mulher não se submeteu às regras impostas, por isso apresenta um "ziguezague" de eus que fissura a ortodoxia das representações sociais (cf. RICHARD, 2002, p. 166). Assim, As doze cores do vermelho retoma a tradição da protagonista transgressora de um espaço pós-moderno por questionar a identidade fixa, ao explorar a "fantasia" e a subjetividade como elementos fundamentais para construção da identidade da protagonista.

\section{Considerações finais}

Agora vamos tentar melhor respaldar o tanto que a identidade de gênero é representada fora do lugar na literatura de autoria feminina brasileira. Nos romances analisados, as protagonistas articulam seu discurso fora do poder patriarcal. Elas partem em busca de novos espaços fora da identidade fixa que lhes é imposta. Assim, elas se movimentam entre o poder do "pai" e o prazer da transgressão, como nos ensina Michel Foucault. Nesse jogo, poder e prazer são metáforas de um sistema de opressão, pois há o "prazer que se abrasa por ter que escapar a esse poder, fugir-lhe, enganá-lo ou travesti-lo", e há também o "poder que se deixa invadir pelo prazer que persegue e, diante dele, poder que se afirma no prazer de mostrar-se, de escandalizar ou de resistir" (FOUCAULT, 1997, p. 45). Nesse jogo, as escritoras brasileiras, em diferentes contextos históricos, intensificaram a luta da mulher por espaços que não repetissem a opressão da família como única saída para a mulher moderna. Portanto, com a morte das protagonistas, 
seja metaforicamente ou fisicamente, essas obras denunciam a opressão patriarcal por meio do efeito patético da morte. Nesse sentido, o texto literário assume uma condição pedagógica, por destacar a opressão patriarcal como um dos motivos da morte, tornando visível e "risível" o processo de naturalização das regras de gênero que historicamente foram impostas.

Como venho argumentando, apesar do final trágico dos romances analisados, defendo o não-lugar da identidade de gênero como um lugar original da literatura brasileira. Isso pode ser assinalado tanto pelo campo estético, como pelo social. No primeiro, cada obra proporciona diferentes leituras metafóricas da morte e da viagem para a mulher, abrindo o texto para novas leituras. No segundo, essas obras denunciam a tirania de um sistema que impõe o homogêneo como natural. Além disso, tornase relevante a ideia de que uma identidade de gênero não está sujeita apenas à coerência interna de ser homem ou ser mulher, visto que a performance de gênero também pode ser uma ferramenta de contestação da lógica social.

Daí, nossa defesa do avanço na representação de gênero que cada obra significa para a literatura brasileira. As duas primeiras, pelo caráter inovador das abordagens, pois, tanto a condição líquida de Virgínia, em O lustre, como a identidade em trânsito de Virgínia, em Ciranda de pedra, ressaltam o poder de desconstrução das representações tradicionais da mulher. Já as duas posteriores destacam o caráter paródico de representação da família. Tanto Renata, em O quarto fechado, com o metafórico enterro da identidade patriarcal, como a pintora, em As doze cores do vermelho, com a patética morte da protagonista, podem ser analisadas como identidades femininas que trazem elementos estéticos de zombaria do sistema patriarcal.

Nessas obras, a não completude social da protagonista pode parecer uma opção retrógrada. No entanto, o que para o/a leitor/a pode ser visto como uma incoerência social, no plano estético, significa uma ruptura 
de padrão, um deslocar o fixo, visto que "o gênero não se constitui de maneira coerente ou consistente nos diferentes contextos históricos" (BUTLER, 2003, p. 20). Ora, com isso, podemos perceber que a necessidade de um final feliz para a protagonista transgressora é fruto mais do desejo do/a leitor/a que da lógica dessas narrativas. Nesse sentido, cabe destacar que cada uma dessas narrativas destaca o quanto o pertencimento identitário da mulher atravessou as representações ficcionais de autoria feminina do Século XX.

Portanto, a coerência que destaco dessas representações identitárias é o fato de elas se pautarem por uma não-coerência para a identidade fixa. Com isso, o trabalho estético de cada obra contribui para novas interpretações, que ampliam a capacidade transgressiva do texto literário. Como nos ensina Butler, não é necessário haver um agente por trás do ato, uma vez que, "no e através do ato", a identidade se projeta com uma manifestação de gênero (cf. BUTLER, 2003). Mesmo sem o final feliz, cada uma das obras analisadas ressalta a identidade de gênero fora do lugar. Esse não-lugar é retomado de diferentes formas como um lugar legítimo para a identidade da mulher. Com isso, a ideia do nãolugar da identidade de gênero na literatura brasileira ressalta uma estética própria do feminismo das diferenças, aquele que não está preocupado em construir uma oposição fixa, mas sim assinalar "registros heterogêneos, plurais e contraditórios, de identificação sexual, de representação social e significação cultural” (RICHARD, 2002, p. 155). 


\section{Referências}

BAUMAN, Zygmunt. Identidade. Entrevista a Benedetto Vecchi. Tradução Carlos A. Medeiros. Rio de Janeiro: Jorge Zahar, 2005.

BUTLER, Judith. Problemas de gênero. Tradução de Renato Aguiar. Rio de Janeiro: Civilização Brasileira, 2003.

BUTLER, Judith. Corpos que pesam: sobre os limites discursivos do "sexo". In LOURO, Guacira Lopes. O corpo educado. Belo Horizonte: Autêntica, 2001.

CUNHA, Helena Parente. As doze cores do vermelho. Rio de Janeiro: Tempo Brasileiro, 1998.

FOUCAULT, Michel. A vontade de saber. Rio de Janeiro: Graal, 1997.

HALL, Stuart. A identidade cultural na pós-modernidade. Tradução de Tomaz Tadeu da Silva e Guacira Lopes Louro. 3 ed. Rio de Janeiro: DP\&A, 1999.

HALL, Stuart. Quem precisa da identidade? In: SILVA, Tomaz Tadeu da (org.). Identidade e diferença. Petrópolis: Vozes, 2000.

HUTCHEON, Linda. Poética do pós-modernismo. Tradução Ricardo Cruz. Rio de Janeiro: Jorge Zahar, 1991.

LAURETIS, Teresa de. A tecnologia do gênero. In:

HOLLANDA, Heloísa Buarque de. Tendências e impasses. Rio de Janeiro: Rocco, 1994.

LISPECTOR, Clarice. Olustre. Rio de Janeiro: Rocco, 1999.

LOURO, Guaraci Lopes. O corpo educado. Belo Horizonte: Autêntica, 2001.

LUFT, Lya. O quarto fechado. 4. ed. São Paulo: Siciliano, 1991. 
NUNES, Benedito. O drama da linguagem - uma leitura de

Clarice Lispector. 2. ed. São Paulo: Ática, 2005.

PINTO, Cristina Ferreira. O Bildungsroman feminino: quatro exemplos brasileiros. São Paulo: Perspectiva, 1990.

RICHARD, Nelly. Intervenções críticas. Tradução Rômulo Monte Alto. Belo Horizonte: UFMG, 2002.

TELLES, Lygia Fagundes. Ciranda de pedra. 31 ed. Rio de Janeiro: Rocco, 1998.

XAVIER, Elódia. Declínio do patriarcado. Rio de Janeiro: Rosa dos Tempos. 1998.

XAVIER, Elódia. Para além do cânone. In: RAMALHO, Cristina (org.). Literatura e feminismos. propostas teóricas e reflexões críticas. Rio de Janeiro: Elo, 1999. 